\title{
A importância dos estudos sobre interiorização da universidade e reestruturação territorial
}

L'importance des études sur l'intériorisation de l'université et restructuration territoriale

The importance of studies about the university and territorial restructuring La importancia de los estudios acerca de la interiorización de la universidad y reestructuración territorial

\section{Leonardo Chagas de Brito}

\section{OpenEdition}

\section{Journals}

\section{Edição electrónica}

URL: http://journals.openedition.org/espacoeconomia/802

DOI: 10.4000/espacoeconomia.802

ISSN: 2317-7837

\section{Editora}

Núcleo de Pesquisa Espaço \& Economia

\section{Refêrencia eletrónica}

Leonardo Chagas de Brito, « A importância dos estudos sobre interiorização da universidade e reestruturação territorial », Espaço e Economia [Online], 4 | 2014, posto online no dia 14 novembro 2014, consultado o 19 abril 2019. URL : http://journals.openedition.org/espacoeconomia/802 ; DOI : 10.4000/espacoeconomia.802

Este documento foi criado de forma automática no dia 19 Abril 2019. 


\title{
A importância dos estudos sobre interiorização da universidade e reestruturação territorial
}

\author{
L'importance des études sur l'intériorisation de l'université et restructuration \\ territoriale \\ The importance of studies about the university and territorial restructuring \\ La importancia de los estudios acerca de la interiorización de la universidad y \\ reestructuración territorial
}

Leonardo Chagas de Brito

\section{Introdução}

1 Devido ao processo de reestruturação territorial em curso no estado do Rio de Janeiro, observado principalmente a partir da década de 1990, consideramos que há maior intensificação e diversificação das atividades sócio-econômicas, e, por conseguinte, as regiões que estão inseridas nesse processo ganham novos conteúdos no território. Segundo nosso entendimento, as Instituições de Ensino Superior (IES) públicas fazem parte destes novos conteúdos. São as políticas públicas de interiorização de tais instituições no Estado do Rio de Janeiro que pretendemos pesquisar, entendendo-as como uma das constituintes da reestruturação territorial e da expansão do tecido urbano (ou urbanidade).

2 Segundo este olhar, as repercussões dessa interiorização relacionam-se com as transformações não só econômicas, mas também sociais e espaciais, considerando, por exemplo, a mobilidade populacional, os fluxos de maneira geral, maior integração do território e novas sociabilidades. Acreditamos, assim, ser importante relacionar a interiorização da universidade a uma série de tendências nacionais e internacionais e também, no interior do próprio estado fluminense, suas regiões e localidades - ou seja, em escalas mais próximas. 
3 Essa interiorização, que ocorreu e ocorre com a participação intensiva de prefeituras e parcerias com agentes econômicos, tem um duplo papel de resultante e provedora das transformações atuais no local/regional do território fluminense. Consideramos que a interiorização da educação superior pode ser tratada tanto como mais um fixo, produto da expansão do tecido urbano (ou da urbanidade) e da reestruturação territorial com um todo e, dialeticamente, um agente, na medida em que possibilita maior intensificação dos fluxos em nível intra-regional e inter-regional.

4 Na década de 1990 foi uma instituição estadual, a UERJ (Universidade do Estado do Rio de Janeiro), que mais interiorizou e expandiu suas instalações. A política neoliberal do Governo Federal de desmonte do setor público foi a principal causa da não expansão das instituições federais em tal década - algo que não aconteceu com a UERJ, ainda que o Estado do Rio de Janeiro estivesse nesse mesmo contexto. Por outro lado, a chegada de novos investimentos industriais reestruturou economicamente certas localidades e a expansão da UERJ ocorreu como uma continuidade do início do governo Leonel Brizola de maior atenção ao interior fluminense.

5 Da década de 2000 até o atual momento são as IES (Instituições de Ensino Superior) Federais do Rio de Janeiro, como UFRJ (Universidade Federal do Rio de Janeiro), UFF (Universidade Federal Fluminense) e UFRRJ(Universidade Federal Rural do Rio de Janeiro), que lideram tal processo, a partir da gestão de Luís Inácio Lula da Silva em função do REUNI (Reestruturação e Expansão das Universidades Federais).

6 Um dos pontos principais de nosso trabalho é a comparação entre a interiorização das IES Federais e Estadual em um mesmo estado em décadas seguidas distintas, possibilitando uma análise de suas semelhanças e diferenças sobre tal processo. Apesar das diferentes escalas de governo e de temporalidades, o comum é que não é a estrutura universitária em sua plenitude que se interioriza, mas sim, fragmentos como faculdades, institutos isolados, núcleos, centros e polos de instituições que tem os campi centrais na metrópole.

7 Assim, um questionamento principal emerge: Qual (is) o(s) sentido(s) da expansão $e$ interiorização do Ensino Superior Público? A partir desta indagação central, outras questões podem ser identificadas: [i] Como podemos compreender tais políticas públicas de diferentes esferas de governos (federal e estadual) tendo como recorte espacial o estado do Rio de Janeiro a partir da déa partir da ddo Rio de Janeiro?stado do Rio de Janeiro?am criadas entre 2003 e cada de 1990 até os dias atuais? [ii] Que tipos de demandas a interiorização das IES públicas atende? E estas demandas são comuns entre as Regiões? [iii] Como compreender tal processo relacionando às transformações em curso em função da reestruturação territorial de forma ampla?

8 A problemática central é debatermos a importância das políticas públicas de expansão e/ ou interiorização das IES serem produtos/agentes que consolidam bases locais, sustentando determinadas demandas e servindo como um elemento constituinte nas novas dinâmicas territoriais e ampliação do tecido urbano no Estado do Rio de Janeiro, seja sob a forma de atrativo, elemento constitutivo ou ainda como suporte posterior.

9 Consideramos que nossa proposta de tema seja relevante, pois praticamente todas as universidades públicas tradicionais (federais e estaduais) do estado do Rio de Janeiro se interiorizaram e/ou expandiram, principalmente a partir da década de 1990. O que nos chama atenção é que tal assunto não tem sido acompanhado com um interesse maior dos que lidam com questões referentes à reestruturação territorial, ampliação do tecido urbano e políticas públicas, ou com estudos mais amplos sobre a geografia das universidades. 

trabalho, que é relacionar a interiorização da universidade com os debates sobre a reestruturação territorial - julgamos oportuno debater o papel da universidade dentro de uma estrutura político-econômica brasileira nos últimos 20 anos e as políticas públicas na/da Educação Superior. É intenção também explorar o processo de privatização das universidades públicas (que tem várias facetas, para além da simples entrega à iniciativa privada), a ampliação da rede privada de Ensino Superior e toda a intencionalidade do capital que existe no discurso da "qualificação do trabalho" e da qualificação do território diante da competição entre os lugares para a atração de investimentos.

15 A seguir, nosso escopo é elucidar o atual processo de interiorização das IES federais no Brasil, dando destaque para o projeto REUNI do Governo Lula, que servirá como base de um contexto para explicar o processo de interiorização das universidades públicas federais no Estado do Rio de Janeiro, e por que não, contrapor com o processo de interiorização das IES estaduais na década de 1990. ocorrendo no Estado do Rio de Janeiro, sobretudo a partir da década de 1990, considerando aspectos econômicos gerais, novas instalações industriais, crescimento populacional, desenvolvimento de algumas cidades e regiões e expansão da metrópole.

Por último, entre possibilidades e impossibilidades relacionar a interiorização das IES públicas no Estado do Rio de Janeiro com o processo de reestruturação territorial, englobando desde os aspectos econômicos sobre a qualificação do trabalho até a própria qualificação do território envolvendo a "guerra dos lugares", nosso intento é pensar os impactos nas sociabilidades e o próprio simbolismo que a instituição "universidade" representa como urbanidade em um contexto de requalificação urbana.

\section{Indicações teórico-metodológicas}

Com relação aos dados e informações sobre a interiorização e expansão das IES públicas, temos como principais fontes documentos, artigos e notícias de veículos oficiais como o MEC (Ministério da Educação) e as próprias informações na rede disponíveis nos sítios de IES interiorizadas. territorial não podemos abandonar a perspectiva de análise relacionada à reestruturação 
do papel do Estado, da reestruturação produtiva no que se refere à aplicação de tecnologia no interior da fábrica, a diversificação da produção e a localização de novos empreendimentos a partir do paradigma das vantagens comparativas (SCOTT, 1999; STORPER, 1997; HARVEY, 1992), mudanças no mundo do trabalho, além dos avanços tecnológicos nos meios de comunicação e transporte, caracterizando o período meiotécnico-científico-informacional (SANTOS, 1996).

Sobre a reestruturação territorial no Estado do Rio de Janeiro, temos como referências principais os trabalhos de LIMONAD, 1996, 2004; NATAL, 2004, 2005, 2007,2009 e; OLIVEIRA, 2003. Já no que se refere às políticas públicas de interiorização das IES vinculados aos processos do desenvolvimento regional e reestruturação territorial, temos como principais bases preliminares ARAUJO 2013, BOISER, 1986, DOURADO, 2001; ROLEURS, 1993; TAVARES, 2004. É a partir desses autores que nos aprofundaremos teoricamente e metodologicamente para entender especificamente a proposta de nosso trabalho que é a interiorização das IES públicas no Estado do Rio de Janeiro.

Como algo secundário no desenvolvimento do trabalho, na tentativa de ampliar o debate, acreditamos que também exista uma demanda simbólica por IES públicas pelo fato das mesmas representarem mais urbanidade, centralidade e inserção nos fluxos da metrópole e nas localidades que recebem tais instituições, ampliando o "urbanismo como modo de vida" - Para tal, temos como principais referências, de acordo com leituras preliminares, BOURDIEU, 1992; CHOAY, 2010; LEFEBVRE, 2002; SIMMEL in VELHO, 1976 e 2002 e2005; RIBEIRO, 1996; e WIRTH, 1976.

Um dos estudiosos sobre o assunto, nos mostra que a interiorização das IES públicas está vinculada aos interesses e participação do poder municipal, fundações educacionais e empresas locais quando se refere à Universidade Federal de Goiás (UFG).

Os resultados obtidos nesta pesquisa levam à conclusão de que as políticas adotadas pelo Estado brasileiro, em que pesem as peculiaridades regionais ou locais, são sempre orientadas por prioridades, vínculos interesses e compromissos nem sempre manifestos, mas reveladores de procedimentos políticos com determinados e almejados fins (DOURADO, 2001, p. 177a).

O autor vai além ao afirmar que tal política pública nada mais é do que um clientelismo devido às parcerias não só com a prefeitura, mas também, com empresas locais.

No âmbito dessas políticas, situam-se as experiências de privatização que têm sido implementadas no campo educacional: a defesa da terceirização, da parceria escolaempresa, das cooperativas de ensino, dos convênios e dos contratos de prestação de serviços. Foi nosso propósito resgatar a consolidação dessas políticas de privatização por meio da análise das modalidades de expansão e interiorização do ensino superior em Goiás na década de $80(. .$.$) A articulação das políticas de$ expansão - ampliação das oportunidades, próeducacionais - e de interiorização do ensino superior no interior do Estado de Goiás efetivou-se, portanto, com base na interligação entre as esferas pública e privada, num processo mediatizado por práticas clientelistas - acordos e barganhas políticas - lesivas ao patrimônio público.

O discurso legitimador desse processo, assentado na defesa da dinamização da economia regional e na sua conseqüente integração à lógica do mercado, faz uso de artifícios político-ideológicos para legitimar a adoção de tais políticas. Assim, o discurso que prevaleceu foi o do ensino superior como fator de progresso, de desenvolvimento e integração e, sobretudo, como fator de status e prestígio (DOURADO, 2001, p. 178b). 
O trabalho de Dourado já nos abre um horizonte para compreendermos como as políticas públicas de interiorização e expansão das IES, tanto do Governo do Estado do Rio de Janeiro, sobretudo na década de 1990, quanto do Governo Federal, com o REUNI nos anos 2000. Ambos os processos estão relacionados com o processo de reestruturação territorial iniciado há mais ou menos vinte anos no estado do Rio de Janeiro.

\section{A atual expansão e interiorização da educação superior pública no debate do desenvolvimento urbano-regional: entre a democratização e a instrumentalização}

Diante de todo de um entorno ideológico instrumentalizado e praticado pelos ditames neoliberais com relação à educação como um todo a partir da década de 1990, e no nosso caso, o Ensino Superior, o Decreto 2306/97 autorizou a "diversificação" da/na educação superior para ampliar as vagas como um todo, contribuindo significativamente para expansão do setor privado, permitindo a criação de fragmentos de uma estrutura universitária, como faculdades e instituto. Tal flexibilização não só foi uma oportunidade para as IES privadas (que, sobretudo, foram as que mais se beneficiaram com esta lei), mas também para as IES públicas.

Neste mister, esclarece objetivamente a admissibilidade de formas jurídicas de natureza civil, fundacional ou comercial, e indica cinco categorias de organização acadêmica: I- Universidades, II- Centros Universitários, III- Faculdades Integradas, IV- Faculdades e V- Institutos Superiores ou Escolas Superiores (art. 8º ). As universidades são caracterizadas, como tradicionalmente, pela indissociabilidade de ensino, pesquisa e extensão, admitindo-se a inovação de universidades especializadas. (LUCE, 16:2001).

Atualmente, parece que a fragmentação e interiorização das IES públicas se assemelham aos mesmos moldes e caminhos da interiorização e fragmentação industrial observadas no nos últimos vinte anos, num invólucro de uma especialização do local.

Sobre o REUNI e suas intenções, destacamos um pequeno texto explicativo extraído do seu sítio oficial do MEC na internet.

A expansão da educação superior conta com o Programa de Apoio a Planos de Reestruturação e Expansão das Universidades Federais (Reuni), que tem como principal objetivo ampliar o acesso e a permanência na educação superior. Com o Reuni, o governo federal adotou uma série de medidas para retomar o crescimento do ensino superior público, criando condições para que as universidades federais promovam a expansão física, acadêmica e pedagógica da rede federal de educação superior. Os efeitos da iniciativa podem ser percebidos pelos expressivos números da expansão, iniciada em 2003 e com previsão de conclusão até 2012.

As ações do programa contemplam o aumento de vagas nos cursos de graduação, a ampliação da oferta de cursos noturnos, a promoção de inovações pedagógicas e o combate à evasão, entre outras metas que têm o propósito de diminuir as desigualdades sociais no país.

O Reuni foi instituído pelo Decreto nº 6.096, de 24 de abril de 2007, e é uma das ações que integram o Plano de Desenvolvimento da Educação (PDE).

Num primeiro momento, pelo que nos é apresentado, os objetivos do REUNI estão aparentemente vinculados à questão da ampliação do acesso e desenvolvimento social e econômico. Mas, em um slide de uma apresentação sobre o programa, o tema 
desenvolvimento regional e redução das desigualdades territoriais ficam cada vez mais evidentes. Dentre os objetivos gerais destacamos trechos em slides do MEC sobre a apresentação do Programa REUNI:

"Objetivos Gerais:

Expandir, ampliar, interiorizar e consolidar a rede de Institutos e Universidades Federais, democratizando e ampliando o acesso de vagas na Educação Profissional, Tecnológica e Superior

Promover a formação de profissionais qualificados, fomentando o desenvolvimento regional $e$ estimulando a permanência de profissionais qualificados no interior do Brasil;

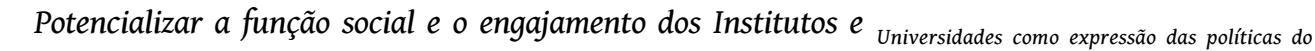
Governo Federal na superação da miséria e na redução das iniquidades sociais e territoriais."

E a partir dos objetivos gerais, são apresentadas as três dimensões que o processo de interiorização e expansão inseridas no REUNI pretendem atingir:

\section{“1 - DIMENSÃO SOCIAL:}

Universalização de atendimento aos Territórios da Cidadania;

Atendimento aos municípios populosos e com baixa receita per capita, integrantes do G100 (Grupo das cem cidades brasileiras com receita per capta inferior a $R \$ 1$ mil e com mais de 80 mil habitantes

\section{; Municípios com percentual elevado de extrema pobreza;"}

\section{“2 - DIMENSÃO GEOGRÁFICA:}

Atendimento prioritário aos municípios com mais de 50.000 habitantes ou microrregiões não atendidas;

Universalização do atendimento às mesorregiões brasileiras; Municípios em microrregiões não atendidas por escolas federais;

Interiorização da oferta pública de Educação Profissional e Ensino Superior;

Oferta de Educação Superior Federal por estado abaixo da média nacional."

“3 - DIMENSÃO DE DESENVOLVIMENTO:

Municípios com Arranjos Produtivos Locais - APLs identificados;

Entorno de grandes investimentos".

A análise de Dourado (2001) citada anteriormente - antes mesmo do Programa REUNI, que começou a ser aplicado em 2003 - já nos abre um horizonte para compreendermos como no governo de Luís Inácio Lula da Silva, tais políticas públicas de interiorização e expansão podem também estar sendo orientadas.

48 A partir dessa política pública, de fato há uma possibilidade de ingresso de alunos em áreas menos favorecidas e distantes das universidades públicas dos grandes centros, além da ampliação do acesso à educação superior que sem dúvida alguma é louvável a começar pelos investimentos na ampliação de pessoal.

Só para atender à demanda das novas instituições, foram criados 3.840 cargos, dos quais 2.365 para professores e 1.475 para técnicos, além de 120 de direção e 420 funções gratificadas. Na primeira etapa do programa, até 2007, serão oferecidas 30 mil vagas. O MEC, depois de negociar com o Ministério do Planejamento, já autorizou a realização de concursos destinados à contratação de 24.776 professores e técnicos. Desde 2003, foram liberadas 9.008 vagas para professores universitários, 1.780 para professores de primeiro e segundo graus e 13.988 para técnicos 
administrativos. Até 2010, a expansão deve gerar 125 mil matrículas nas instituições federais, um crescimento de $21,75 \%$ sobre 574.584 matrículas (censo de 2004) da rede federal de ensino superior (ASSESSORIA DE COMUNICAÇÃO SOCIAL/MEC, 28/07/2006).

Dados mais atualizados mostram quantas universidades foram criadas entre 2003 e 2011, como veremos na citação e no gráfico a seguir.

A expansão da Rede Federal de Educação Superior teve início em 2003 com a interiorização dos campi das universidades federais. Com isso, o número de municípios atendidos pelas universidades passou de $114 \mathrm{em} 2003$ para 237 até o final de 2011. Desde o início da expansão foram criadas 14 novas universidades e mais de 100 novos campi que possibilitaram a ampliação de vagas e a criação de novos cursos de graduação. (http://reuni.mec.gov.br/index.php? option=com_content\&view=article\&id=100\&Itemid=81)

Fig 1: Expansão das Universidades Federais

\section{Universidades Federais}

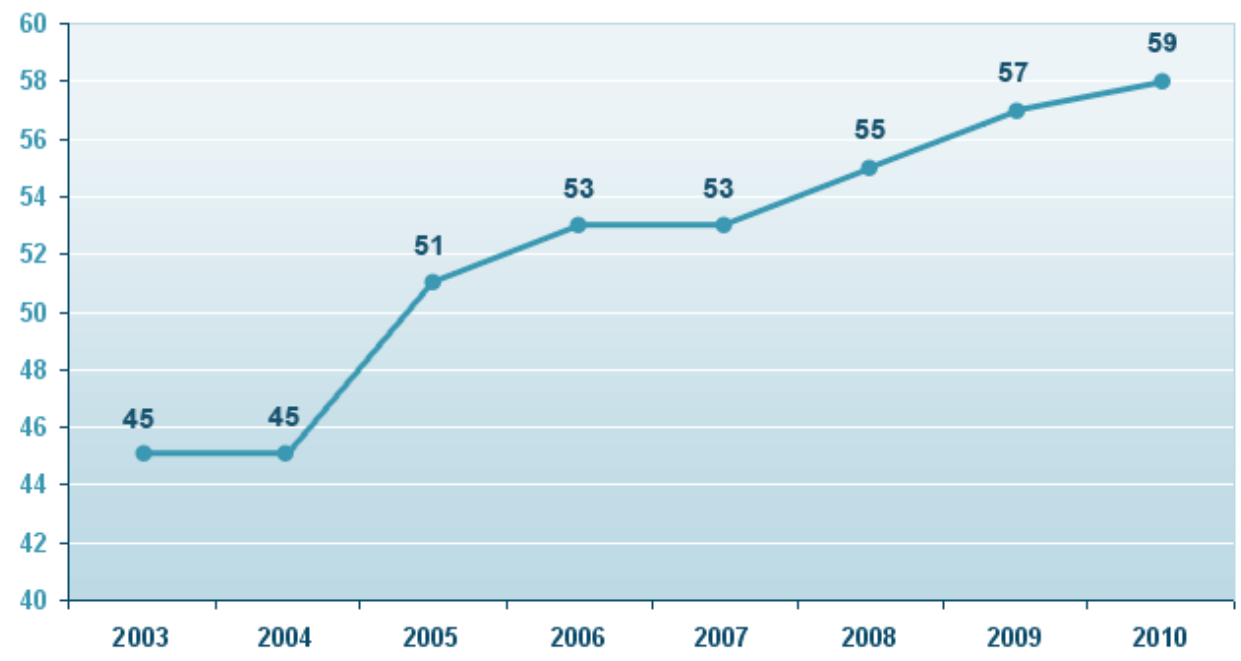

Fonte : Ministério da Educação

50 Os mapas abaixo mostram o crescimento mais especificado dos campi, não só da criação de universidades: 
Fig 2 : Brasil: Localização dos campi das Universidades Federais em 2002

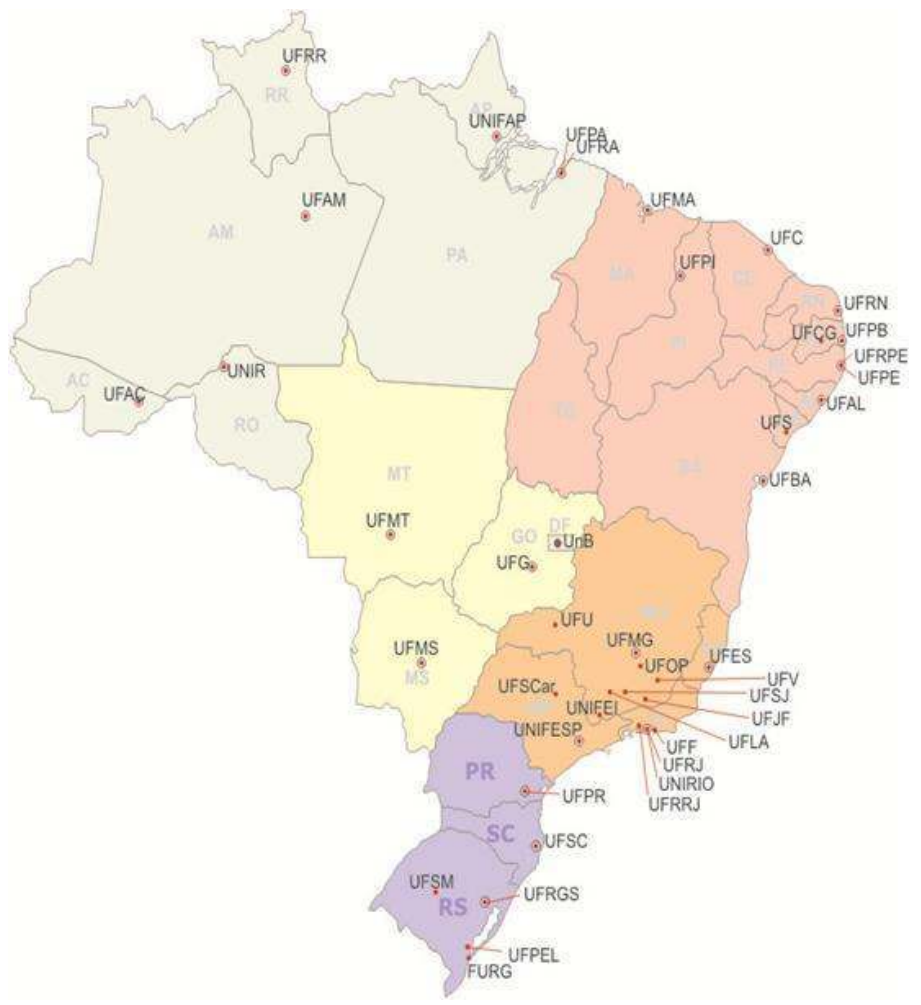

Fonte: Ministério da Educação

Fig 3 : Brasil: Localização dos campi das Universidades Federais em 2010

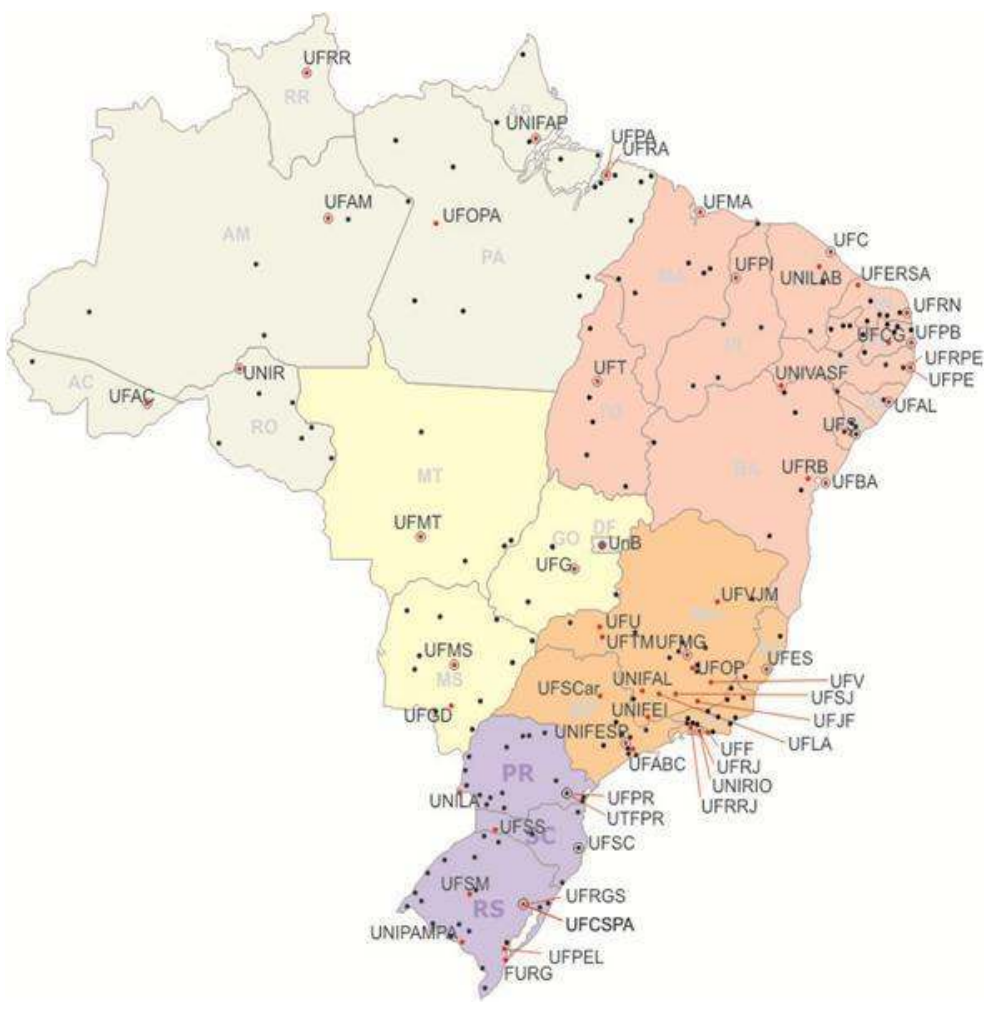

Fonte: Ministério da Educação 
51 Segundo Araújo (2013), a expansão da universidade pública é hoje uma das principais políticas setoriais num processo contraditório de "desenvolvimento urbano-regional", ainda que seja difícil identificar tal política como algo relacionado à grandes projetos de integração e desenvolvimento regional de uma maneira mais efetiva.

“...vale salientar que muitas delas foram muito importantes para o bom desempenho apresentado pelas regiões mais pobres do país no Governo Lula, como ficou antes evidenciado. Uma das mais importantes: a de educação superior teve uma expressão regional positiva..."

Como cada vez mais os investimentos em educação são considerados estratégicos para a promoção do desenvolvimento regional, tal tendência da política educacional brasileira merece referência especial. Vale ainda salientar que as mesmas tendências aqui destacadas para o ensino superior, se repetem na política de ensino médio e profissional. A oferta se expandiu muito no período do Governo Lula e as escolas também se interiorizaram e buscaram as regiões menos desenvolvidas do país.

Acreditamos que a principal importância do processo de interiorização das IES públicas seja a democratização do acesso ao Ensino Superior e isso o próprio REUNI deixa claro. E entendemos que para Araújo essa democratização, ainda que seja uma política setorial, de alguma forma já significa um desenvolvimento regional.

Dentro deste contexto, é importante considerar que forças políticas da esfera municipal e estadual incentivam e contribuem para a instalação das IES, tendo como perspectiva o ganho de "competitividade" - por formar uma força de trabalho qualificada - das localidades dentro da lógica dos fatores locacionais de investimentos. Assim, entendemos que quanto maior for a "qualificação" do trabalho de um município/região, maior a possibilidade de atração de investimentos e integração econômica. Ao mesmo tempo, a região e o local demandam a instalação de campi das IES para passarem a fornecer trabalhadores para as (novas) dinâmicas locais, que também requerem atendimento para saúde, educação e cultura.

Porém, também temos como hipótese que as IES são demandadas na intenção de um ganho de importância local ou regional, no que se refere à algum tipo de hierarquia entre os municípios com o status de polo universitário, que não necessariamente irá se justificar e se vincular apenas ou com nenhuma atividade econômica.

\section{Interiorização das Instituições do Ensino Superior. onde, para quê, para quem, como?}

A partir do que é apresentado pelos documentos oficiais do REUNI podemos entender que a política pública de interiorização da educação superior está relacionada com demandas, sejam elas sociais, políticas ou econômicas. E na realidade, o que se interioriza na grande maioria dos casos são fragmentos de uma estrutura universitária como faculdades, polos, institutos, por exemplo. Tal procedimento é facilitado pelo Decreto 2306/97, já citado anteriormente, que não só foi uma oportunidade para as IES privadas, mas também para as IES públicas a partir do que acabamos de expor.

De fato o REUNI promoveu a criação de Universidades não só nas regiões metropolitanas mas também no interior. Mas tal programa também promove a interiorização de maneira fragmentada, sem uma estrutura de universidade. 

tecnópolis (DROULERS, 1993), particularmente a partir da década de 1990 no estado do Rio de Janeiro; acreditamos ainda que o exemplo citado acima seja importante para dar maior clareza sobre o distanciamento entre política de desenvolvimento regional e a interiorização das instituições de Ensino Superior no processo em curso de reestruturação territorial em tal Estado.Todavia, não acreditamos na ideia de que a interiorização de tais instituições tenha fundamentalmente um papel de ser um "cérebro regional" e criar um "intelligentsia" para pensar e produzir conhecimento para avanços desenvolvimento sócioeconômicos.

A partir disso, ao falar das morfologias históricas e atuais do urbano-regional, percebe-se que em vários momentos as mudanças, quando pensadas a partir de várias ciências com as chancelas dos Estados e de núcleos de produção do saber, não significaram abarcar a necessidade de todos vislumbrando uma vida melhor e mais democrática. Pelo contrário, o que há historicamente é a concentração de aparatos técnicos em uns lugares em detrimento de outros, em função de forças econômicas e políticas que muitas vezes são mútuas.

Muitas vezes a ideia de planejamento se apresenta como uma forma de alocação de recursos, mas criticamos essa postura com base em Oliveira (1987), pois, o próprio planejamento que se pretende meramente técnico acaba em vários momentos servindo para interesses de determinados setores socioeconômicos. $\mathrm{E}$ assim podemos entender que a interiorização das instituições de ensino superior públicas não se distancia desse processo de ser mais um instrumento de qualificação do território a partir de políticas públicas para o desenvolvimento local com base em critérios técnico-mercantis.

Acreditamos que tal processo, na medida em que uma instituição é interiorizada - mesmo fragmentada e impingida pelos ditames instrumentais econômicos ou de mera qualificação profissional e simbólica - pode sim possibilitar novas sociabilidades, convivendo, rompendo e dialogando com as antigas. Não que a universidade tenha um papel de redentora e represente as maiores benfeitorias da modernidade, mas pelo de que ela é, sem sombra de dúvidas, recheada de múltiplas funções e relações sociais que lhes são próprias

612

62 . É a partir destas reflexõesque pretendemos compreender a interiorização das IES públicas no Estado do Rio de Janeiro.

\section{Novas dinâmicas territoriais no Estado do Rio de Janeiro, interiorização das instituições de Ensino Superior Públicas e o debate sobre a reestruturação territorial}

63 Para facilitar a compreensão do que acontece desde a década de 1990 no Estado, vamos enumerar:

641 - Novas instalações industriais (multinacionais e nacionais) que fazem parte de um projeto de reestruturação produtiva desconcentrado dos grandes conglomerados urbanos, que buscam incentivos fiscais e mão-de-obra mais em conta além de outras vantagens comparativas (caso principalmente do Médio Vale Paraíba do Sul); 
mpliação do tecido urbano entre a Região Metropolitana e as Regiões mais próximas (casos das Baixadas Litorâneas, Região Serrana e Costa Verde) devido à fixação da classe média urbana carioca como primeira residência;

3 - Aumento da produção petrolífera, instalação de novos estabelecimentos do setor e maiores ganhos das prefeituras com royalties da exploração do petróleo da Bacia de Campos, (casos das Baixadas Litorâneas e Região do Norte Fluminense);

4 - A ampliação do tecido urbano (ou urbanidades) da Região Metropolitana do Rio de Janeiro devido a maiores fluxos, ampliação das redes técnicas-informacionais e infraestrutura de transporte e o próprio crescimento populacional.

As transformações tem seguido um sentido amplo no território fluminense por abarcar a reestruturação das indústrias, dos meios de circulação e da própria distribuição geográfica dos setores e das atividades econômicas. O que deu origem a um mapa de tendências de arranjo espacial ou a uma regionalização centrada em espaços especializados ("pontos" ou, assim chamados "pólos") e áreas de crescimento demográfico (manchas) ao longo dos grandes eixos viários que cruzam o estado: a BR-116 (Rodovia Presidente Dutra) atravessa a área mais industrializada do Médio Vale do Paraíba (o "pólo" metal mecânico) até a Região Metropolitana; b) a BR-040 cruza o "pólo" gás-químico industrial de Duque de Caxias e passa pela Região Serrana (o "pólo" tecnológico rumo à Minas Gerais; e a BR 101 que, c) no sentido norte, liga a cidade do Rio de Janeiro à Vitória no Espírito Santo, e atravessa os municípios das Baixadas Litorâneas e da Bacia de Campos "pólo" agro-industrialpetrolífero e d) rumo sul circunda a Baía de Sepetiba e a Baía da Ilha Grande "pólo" portuário-industrial e de turismo de veraneio (LIMONAD, 2001:8)

Consideramos que apesar dessas políticas públicas serem estaduais e federais, o que vai influenciar nas instalações das IES é justamente o nível de desenvolvimento regional e/ou local já consolidado historicamente construído combinado com os processos de reestruturação que ocorrem atualmente. Além disso, de forma geral, as cidades que recebem tais instalações são aquelas com maior centralidade; ou seja, geralmente, as instalações das IES ocorrem quando são maiores as transformações territoriais, o aumento populacional, os investimentos e quando se amplia o nível de integração com a metrópole, com a dinâmica estadual e/ou nacional.

Essas instalações universitárias pelo território fluminense promovem maiores fluxos materiais (transporte de pessoas, cargas e etc.) e imateriais (informações sobre estudos científicos e pesquisas, dados administrativos etc,). A própria estrutura das IES em tais regiões é um fixo que possibilita a ampliação dos fluxos não só entre os campi centrais na metrópole e os interiorizados, mas também, numa perspectiva totalizante, evidenciando ainda mais a integração em certas regiões e localidades no território fluminense. Afinal, "os elementos fixos em cada lugar permitem ações que modificam o próprio lugar" (SANTOS, 1988, p. 77).

A análise dos fluxos é às vezes difícil, pela ausência de dados. Mas o estudo dos fixos permite uma abordagem mais cômoda, através dos objetos localizados: agências de correio, sucursais bancárias, escolas, fábricas. Cada tipo de fixo surge com suas características que são técnicas e organizacionais. E desse modo cada tipo de fixo corresponde a uma tipologia de fluxo. Um objeto geográfico, um fixo, é um objeto técnico mas também um objeto social, graças aos fluxos. Fixos e fluxos interagem e se alteram mutuamente (SANTOS, 1988, p. 78)

Oliveira (2003 e 2008) nos possibilita uma noção geral no que se refere às novas dinâmicas tanto na Região Metropolitana como no interior fluminense, em que não há um processo 
de desconcentração metropolitana, mas sim, uma reconfiguração e expansão da metrópole.

“Trata-se, no entanto, de um processo relacionado não só a ações de empresas e grupos econômicos globalizados, mas também a mudanças nas relações políticas e sociais ocorridas em escalas mais próximas; um processo que sinaliza uma reestruturação industrial no interior do estado, simultaneamente a uma inflexão da tendência histórica de hiper-concentração de recursos, arrecadação e população na metrópole" (OLIVEIRA, 2003, p. 15)

"Isso é corroborado pelo fato de que, para além desse movimento de dispersão que incorpora, ainda que de forma fragmentada, espaços do interior à dinâmica territorial metropolitana - ocorre, também, a própria expansão física do tecido urbano no entorno da metrópole, evidenciando que novas formas de expansão estão ocorrendo..." (OLIVEIRA, 2008a, p. 5).

71 O Estado tem um papel fundamental no processo de reestruturação territorial, não somente a partir de incentivos, isenções de impostos e oferecimento de infraestrutura, mas também com a implementação de políticas públicas de expansão institucional representado, neste caso, pela instituição "universidade".

Apesar de tais políticas públicas serem federais e estaduais, consideramos que o que vai influenciar as instalações das IES é justamente o nível de desenvolvimento regional historicamente construído e a intensidade das novas dinâmicas que ocorrem ligadas, principalmente, ao nível de urbanização de cada cidade ou região. Além disso, de forma geral, as cidades que recebem tais instalações são aquelas com maior centralidade.

Entendemos que tais IES públicas contribuem como elementos de "qualificação do trabalho", "qualificando", a rigor, as regiões nas perspectivas econômicas, sociais e espaciais. Dialeticamente, as regiões demandam IES para atender interesses não só de demandas econômicas, como também outros tipos (educação, assistência, saúde) e interesses (políticas para consolidação de bases locais). Assim, não podemos simplesmente relacionar tal interiorização com algo especificamente econômico e para qualificação do trabalho destinada ao setor produtivo. Várias destas instituições interiorizadas visam formar profissionais que atendam também uma demanda por serviços ligados às demandas da educação, saúde, assistência etc., além de possibilitar pesquisas como um todo e para diversas demandas regionais. Além disso, consideramos que tal instituição tem um grande peso simbólico representando certo ar de "modernização" e urbanidade. Ou seja, o que move tal processo também advém de símbolos e representações relacionadas à instituição "universidade", que é uma instituição citadina em sua origem, principalmente na modernidade.

Principalmente no Brasil, as IES públicas possuem uma grande representação simbólica, tendo em vista sua importância na produção de ciência e na formação para o trabalho no cenário nacional e internacional, mesmo que tais instituições no capitalismo periférico não tenha o mesmo papel que nos países centrais em alguns aspectos, principalmente na produção científica e tecnológica. Mas, ainda assim, uma Instituição Superior Pública com a matriz na metrópole vincula e aproxima ainda mais essas cidades dos fluxos nacionais e globais no que se refere à inserção no circuito da "sociedade do conhecimento".

De maneira geral, as cidades que recebem tais instalações são aquelas com maior centralidade. Esses campi não são instalados em qualquer município ou em municípios que predominam ruralidades. Eles já detêm um bom nível de urbanidade e em muitos casos (se não todos), já existem instituições de ensino superior de cunho privado ou filantrópico. A interiorização está ocorrendo nos municípios onde são maiores as 
transformações locais e/ou regionais como o aumento populacional, os investimentos industriais e de variadas atividades econômicas e quando se amplia o nível de integração com a metrópole e com a dinâmica estadual, nacional e internacional.

Consideramos que a interiorização das IES públicas é uma urbanidade resultantecondicionante da expansão da metrópole, ampliando e consolidando o conjunto de fluxos e fixos com outras regiões e localidades. O que justifica isso é que os fragmentos de universidade interiorizados são oriundos de universidades que estão na metrópole e o contexto dos índices de urbanização no Estado do Rio de Janeiro ser o maior do Brasil.

Ainda que essas cidades tenham certo nível de urbanidade anterior, elas demandam, a partir de seus agentes, mais urbanidade para se consolidarem numa perspectiva qualitativa, relacionada à intensidade de objetos e ações, que geralmente se encontram numa metrópole, concentrando atividades, aparelhos e instituições urbanas.

“A predominância da cidade, especialmente da grande cidade, poderá ser encarada como uma consequência da concentração, em cidades, de instalações e atividades industriais e comerciais, financeiras e administrativas, de linhas de transporte e de comunicação e de equipamento cultural e recreativo como a imprensa, estações de rádio, teatros, bibliotecas, museus, salas de concerto, óperas, hospitais, INSTITUIÇÕES EDUCACIONAIS, CENTROS DE PESQUISA E PUBLICAÇÃO, organizações profissionais e instituições religiosas e beneficentes" (WIRTH, 1979, p. 93).

A priori, percebemos que a interiorização das IES ocorre principalmente em função de um localismo e não necessariamente a partir de um planejamento e desenvolvimento urbanoregional a partir das ações de Governos Federal e Estadual, que são os indutores, os agentes da interiorização de tais instituições. Mas, de fato, o que une os projetos de interiorização das Universidades Públicas tanto Federais quanto Estadual no Rio de Janeiro (nosso recorte espacial) são medidas pontuais relacionadas a forças econômicas e políticas que demandam "universidade", pois ela qualifica o território e simboliza a consolidação do urbano em tais municípios e localidades.

\section{Considerações finais e impressões momentâneas}

Acreditamos que exista, sim, uma democratização na interiorização e expansão das Instituições de Ensino Superior públicas, mas não sabemos até que ponto podemos relacionar tais processos com algum tipo de sistematização para o planejamento/ desenvolvimento urbano-regional, mediante as políticas públicas entre universidade, esferas de governo e setor privado. 0 que percebemos é o localismo evidenciado pelo processo de reestruturação produtiva e a "guerra dos lugares". E, para além disso, tais instituições são demandadas também por tudo que representa de urbanidade, dando mais credibilidade simbólica ao lugar, consolidando-o dentro de um circuito entre metrópoles regionais, nacionais e internacionais. Ou seja, as instituições entram num entorno de democratização, intencionalidades de qualificação econômica, do trabalho, política e também simbólica diante do processo de reestruturação territorial no Rio de Janeiro a partir da década de 1990. 


\section{BIBLIOGRAFIA}

ARAÚJO, T. B. Desenvolvimento regional brasileiro e políticas públicas federais no Governo Lula in SADER. E (org). 10 Anos de governos pós-neoliberais no Brasil. Rio de Janeiro: Boitempo, 2013. BOISIER, Sergio. Post-scriptum sobre desenvolvimento regional: modelos reais e modelos mentais. Planejamento e políticas públicas 19 (2009).

BOISIER, S. Universidade e desenvolvimento regional. Cadernos IPPUR/UFRJ, Ano VIII, n 2/3, set./dez, 1994.

BORDIEU, P. A reprodução. Rio de Janeiro: Francisco Alves,1992.

BORDIEU, P. Escritos de Educação. Petrópolis: Vozes, 1998.

CHOAY, F. O urbanismo. Coleção estudos, 67. 2010.

CORREA, R. L. A. Estudos sobre a Rede Urbana. Rio de Janeiro: Bertrand Brasil, 2006. v. 1. 310 p

DOURADO, L. F. A interiorização do ensino superior e a privatização do público. Goiânia: Editora da UFG, 2001.

DROULERS, M. Tecnopolos no Brasil e na França. Cadernos IPPUR/UFRJ, ano VII, n 2, set., 1993

Finep divulga chamada pública que atende expansão de 21 Universidades Federais. www.andifes.org.br, 2006.

LEFEBVRE, H. A Revolução Urbana. Belo Horizonte: UFMG, 2002.

LIMONAD, E. Rio de Janeiro, uma nova relação capital-interior? In: LIMONAD, E.; HAESBAERT, R.; MOREIRA R. (orgs.). Brasil século XXI - por uma nova regionalização? Agentes, Processos e Escalas. São Paulo: Max Limonad, 2004.

LIMONAD, E. Interiorização x Metropolização - Desenvolvimento do Interior e Involução Metropolitana: o caso do interior do Rio de Janeiro. In: MOREIRA R. (Org.). A Reestruturação Industrial e Espacial do Estado do Rio de Janeiro. Niterói: PPGEO - UFF GECEL - GERET, 2003, v. 1, p. $129-138$.

LIMONAD, E. Os lugares da Urbanização: o caso do interior fluminense. São Paulo: FAU/USP, Tese de Doutorado, 1996.

FERREIRA, Taísa. Universidades - Expansão para o interior - Governo inicia processo de descentralização do ensino superior. Brasília: Desafios do Desenvolvimento. IPEA, Ano 10, no 76, 2013.

MANCE, A.E. A Universidade em questão: o conhecimento como mediação da cidadania e como instrumento do capital. São Paulo: IFIL, 1999.

NATAL, J. O desenvolvimento econômico do Estado do Rio de Janeiro: uma esfinge a decifrar. Rio de Janeiro: Conjuntura Econômica, 2006 v. X, pp. 2-4.

NATAL, J. Estado do Rio de Janeiro: dinâmicas e dilemas de uma economia e território em transição. Rio de Janeiro: Boletim do Fórum de Estudos Fluminenses, 2002, n. 13, pp. 2-5. 
NATAL, J. ; OLIVEIRA, A. de; MENDONÇA, L.; SILVA, M. O Estado do Rio de Janeiro Pós 95: Dinâmica Econômica, Rede Urbana e Questão Social. Rio de Janeiro: Pubblicati Editora, 2005. v. 1. $284 \mathrm{p}$.

OLIVEIRA, Floriano J. G. de. Reestruturação produtiva e regionalização da economia no território fluminense. São Paulo: USP, Depto ${ }^{\circ}$ de Geografia, Tese de Doutorado, 2003.

REUNI 2008 - Relatório de Primeiro Ano. MEC/SESu/DIFES, 2009.

RIBEIRO, A.C.T. Urbanidade e vida metropolitana. Rio de Janeiro: Jobran, 1996.

RIBEIRO, A. C. T.; PINHEIRO, D. Metropolização e Rede Urbana: perspectivas dos anos 90. Rio de Janeiro: Cadernos IPPUR/UFRJ, v. set., 1990.

SANTOS M. Por uma outra globalização: do pensamento único à consciência universal. Rio de Janeiro: Record, 2006.

SANTOS M. A Universidade: da Intencionalidade à Universalidade In: Anuário do Instituto de Geociências. v. 23, UFRJ, 2000.

SANTOS M. A Natureza do Espaço: técnica e tempo, razão e emoção. São Paulo: Hucitec, 1996.

SANTOS M. Técnica, espaço, tempo: globalização e meio técnico científico informacional. São Paulo: Hucitec, 1994.

SCOTT, Allen J. Regions and the world economy: the coming shape of global production, competition, and political order. OUP Catalogue, 1999.

SILVA, C. A. da. Qualificação profissional na construção do Brasil urbano moderno: secularização e sociedade, modernização e espaço. Rio de Janeiro: Tese de Doutorado, IGEO/UFRJ, 2002.

SIMMEL, G. O Dinheiro na Cultura Moderna, A Divisão do Trabalho como Causa da Diferenciação da Cultura Subjetiva e Objetiva, o Conceito de Tragédia da Cultura e O Indivíduo e a Liberdade, In: SOUZA e ÖELZE, B. (Orgs.) Simmel e a Modernidade. Brasília: UNB, 2005. Segunda Edição, pp. $23 / 118$.

SIMMEL, G. A Metrópole e a Vida Mental, In: Velho, O. (org.). O Fenômeno Urbano. Rio de Janeiro: Zahar Editores, 1976, pp.11/25.

STORPER, Michael. The regional world: territorial development in a global economy. Guilford Press, 1997.

TAVARES, H. M. Universidade, território e desenvolvimento regional. In: FIALHO, N.; HERÉDIA, E.A.. (Org.). América Latina: educação, espaços culturais e teritorialidade. 1.ed.Salvador: Editora da UNEB, 2004, v. 1, p. 125-134.

TORRES, A.C.T. Urbanidade e vida metropolitana. Rio de Janeiro: Jobran, 1996.

WIRTH, L. O urbanismo como modo de vida. In:VELHO, O. (org.). O Fenômeno Urbano. Rio de Janeiro: Zahar Editores, 1976.

\section{NOTAS}

1. http://portal.mec.gov.br/expansao/images/ APRESENTACAO_EXPANSAO_EDUCACAO_SUPERIOR14.pdf

2. "Me propongo neste ocasión presentar algunas ideas, que me parecen básicas, acerca de algo tan complejo e tan esquivo como es el verdadero desarrollo de uma región, un fenômeno más próprio del campo de los processos psico-sociales que de los fenómenos puramente econômicos. 
Quisiera, aún a título exploratório, escrudiñar em lãs relaciones entre el logro de esse esquivo desarrollo y la capaciadad para generar en una región, uma verdadeira inteligencia social, tarea en la qual el papel de una universidad, simultáneamente regional y nacional (...) resulta absolutamente fundamental. No por casualidad, Jacques Boudeville, maestros de tantos regionalistas, decía em vida que la universidade es el cérebro de toda región, aunque a la luz de los conocimientos actuales sobre biologia, processos inteligentes y capacidade de generar pensamiento original, tal vez habría que relativizar la informnación de Boudeville, que ya tiene cuatro décadas, para señalar que la universidade es uno de los cérebros regionales, privilegiado eso si, por la multiplicidade de funciones sociales que lê son próprias" (BOISIER,1994:16).

\section{RESUMOS}

A investigação em curso visa reconhecer a dinâmica espacial da interiorização da universidade pública no Estado do Rio de Janeiro (RJ), destacando os aspectos políticos e sociais que cercam tal processo. Se a interiorização em tela está ligada aos novos padrões de organização da indústria e do urbano no século XXI, isto não significa, no entanto, que podemos relacioná-la somente a políticas de reestruturação territorial.

La recherche en cours vise à reconnaître la dynamique spatiale de l'intériorisation de l'université publique dans l'État de Rio de Janeiro (RJ), en soulignant les traits politiques et sociaux autour de ce processus. Si l'intériorisation en question est liée aux nouveaux modèles d'organisation urbaine et industrielle au XXIe siècle, cela ne signifie pas pourtant qu'on puisse l'associer seulement aux politiques de restructuration territoriale.

This research aims to recognize the spatial dynamics of internalization of the public university in the state of Rio de Janeiro (RJ), analyzing the social and political aspects of this process. If this internalization is linked to new patterns of organization of industry and urban in the 21st century, this does not mean that we can relate it only to policies of territorial restructuring.

Esta investigación tiene como objetivo reconocer la dinámica espacial de la internalización de la universidad pública en el estado de Rio de Janeiro (RJ), en sus aspectos políticos y sociales. Si esta internalización está vinculada a los nuevos patrones de organización de la industria y urbana en el siglo XXI, esto no significa que podamos relacionarlo únicamente con las políticas de reestructuración territorial.

\section{ÍNDICE}

Mots-clés: université publique, intériorisation, industrie, restructuration territoriale, Rio de Janeiro

Palavras-chave: universidade pública, interiorização, indústria, reestruturação territorial, Rio de Janeiro

Palabras claves: universidad pública, internalización, industria, reestructuración territorial, Río de Janeiro

Keywords: public university, internalization, industry, territorial restructuring, Rio de Janeiro 


\section{AUTOR}

\section{LEONARDO CHAGAS DE BRITO}

Graduado em Licenciatura Plena em Geografia - UERJ / FFP, Mestre em Políticas Públicas e Formação Humana pelo PPFH/UERJ e Doutorando em Planejamento Urbano e Regional pelo IPPUR/UFRJ. Bolsista da CAPES - Coordenação de Aperfeiçoamento de Pessoal de Nível Superior. E-mail : lcbgeo@hotmail.com 